\title{
Evolution de la bilirubinémie et de l'activité plasmatique de la $\gamma$ glutamyl transférase chez des agneaux infestés expérimentalement par Fasciola hepatica
}

\author{
S Prache1, P Galtier² \\ 1 Laboratoire de la Production Ovine, INRA, Theix, 63122 Ceyrat; \\ 2 Laboratoire de Pharmacologie Toxicologie, INRA, 180, chemin de Tournefeuille, \\ 31300 Toulouse, France
}

Summary - F hepatica infection of lambs (single dose of 150 metacercariae) increased the plasma $\gamma$-glutamyl transferase (GGT) activity and the total serum bilirubin concentration. Thus it might present a risk of inducing yellow fat. It had no effect on the plasma carotenoid level.

Introduction - La présence de bilirubine et/ou de pigments caroténoides dans le tissu adipeux des ovins peut provoquer une coloration jaune anormale de celui-ci et entraîner un déclassement de la carcasse. Une hyperbilirubinémie peut avoir des origines diverses, et parmi elles, l'obstruction des canaux biliaires provoquée par une fasciolose (Fetcher, 1983; Pulatov et Abdullaev, 1984). Les causes de l'accumulation de pigments caroténoides sont très mal connues. Nous avons voulu étudier l'effet d'une infestation d'agneaux par $F$ hepatica sur l'évolution de la bilirubinémie et du taux de caroténoides sanguins. L'activité plasmatique de la $\gamma$ glutamyl transférase a été utilisée comme indicateur des lésions hépatobiliaires.

Matériel et Méthodes - Quatre agneaux mâles de race Lacaune, pesant de 22 à $26 \mathrm{~kg}$, élevés en bergerie avec un régime constitué de concentré et de paille ont été infestés expérimentalement par 150 métacercaires de $F$ hepatica. Nous avons mesuré la bilirubinémie et l'activité plasmatique de la GGT à partir de kits de dosage Boehringer. Le taux sanguin de caroténoides a été déterminé par la méthode décrite par Karijord (1978). Les données ont été analysées par le test de Wilcoxon.

Résultats et Discussion - L'activité plasmatique initiale de la GGT est normale (fig 1). Elle augmente à partir de la $6^{\circ}$ semaine après infestation, atteint un maximum de $77,4 \mathrm{UI} / \mathrm{l}$ en $10^{\circ}$ semaine, puis diminue. La bilirubinémie initiale est normale, puis s'élève brusquement 8 semaines après l'infestation et continue à augmenter plus modérement pour atteindre $4,5 \mathrm{mg} / \mathrm{l}$ en $26^{\circ}$ semaine. La GGT est libérée dans le sang à la suite des lésions hépatobiliaires. Sa concentration sanguine augmente donc dès l'arrivée des jeunes douves dans le foie, puis retourne à la normale quand les douves sont installées dans les canaux biliaires et que les tissus cicatrisent. L'augmentation de la bilirubinémie résulte de l'obstruction des canaux biliaires par les parasites qui y pénètrent 8 à 10 semaines après avoir été ingérés (Sykes et al, 1980). Cette augmentation est donc plus tardive que celle de la concentration sanguine de la GGT, et s'aggrave avec la croissance des 


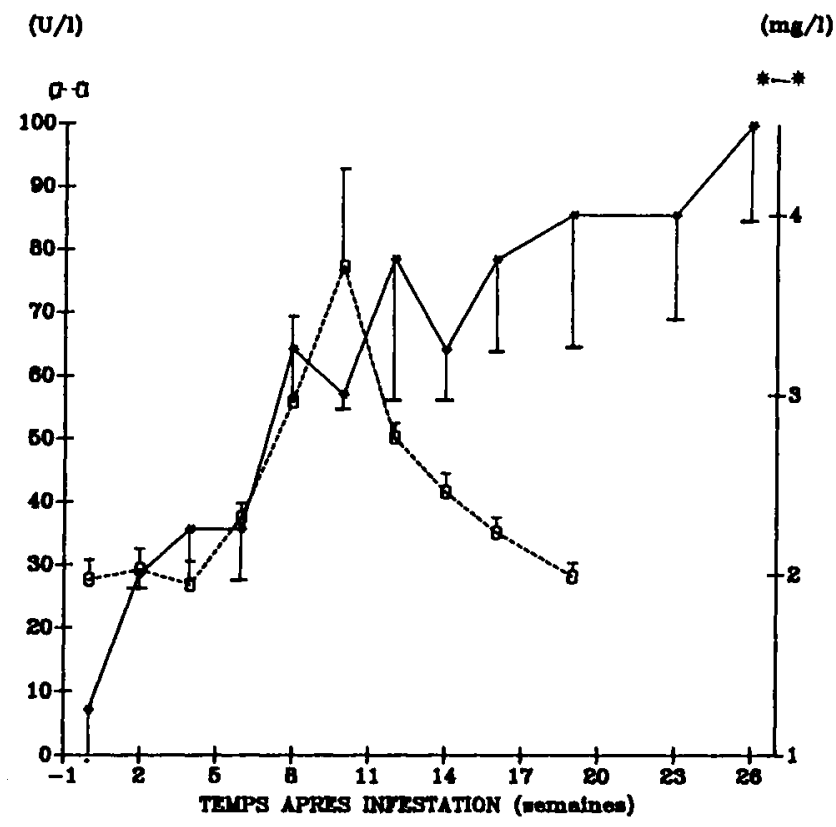

Fig 1. Evolution de la bilirubinémie $(* \rightarrow m g / l)$ et de l'activité plasmatique de la GGT ( $-\square$ UI/I) après infestation d'agneaux par $F$ hepatica (valeur moyenne et écart type de la moyenne). La différence par rapport à la valeur initiale était significative $(P=0,05)$ entre 8 et 26 semaines pour la bilirubine et entre 10 et 16 semaines par la GGT.

douves. Chez les bovins, où la bilirubinémie normale est du même ordre que chez les ovins (Fetcher, 1983), le seuil considéré comme pathologique est de $5 \mathrm{mg} / \mathrm{l}$ (Frerking et al, 1984); toutefois, une bilirubinémie de $3 \mathrm{mg} / \mathrm{l}$ est considérée comme suspecte (Frerking et al, 1984) voire pathologique (Kalchreuter, 1985). Dans notre expérience, les 4 agneaux ont une bilirubinémie supérieure à $3 \mathrm{mg} / \mathrm{l}$ à partir de la $8^{8}$ semaine. Un taux supérieur à $5 \mathrm{mg} / \mathrm{l}$ apparaît pour un animal en $12^{\circ}, 16^{\circ}$ et $19^{\circ} \mathrm{se}$ maine, pour deux en $23^{\circ}$ semaine et trois en $26^{\circ}$ semaine.

Le taux de caroténoides sanguins n'a pas été modifié par l'infestation; il est resté très bas, de l'ordre de $90 \mu \mathrm{g} / \mathrm{l}$, ce qui n'est pas susceptible d'entraîner une coloration jaune du tissu adipeux (Karijord, 1978).
La fasciolose pourrait donc entraîner un risque de coloration jaune du tissu adipeux, par suite d'une hyperbilirubinémie qui s'aggrave au cours du temps; les caroténoides ne sont par contre pas impliqués.

Remerciements - Nous remercions M Renerre (Station Viande, INRA, Theix).

Fetcher A (1983) Vet Clin North Am 5, 525-538 Frerking H, Serur B, Assmus G (1984) Tieraerztl Umsch 39, 749-756

Kalchreuter S (1985) Tieraerztl Umsch 40, 382386

Karijord O (1978) Acta Agric Scand 28, 355-359

Pulatov GS, Abdullaev UA (1984) Tr Uzb Nauchno-Issled Inst Vet 36, 51-56

Sykes AR, Coop RL, Robinson MG (1980) Res Vet Sci 28, 71-75 